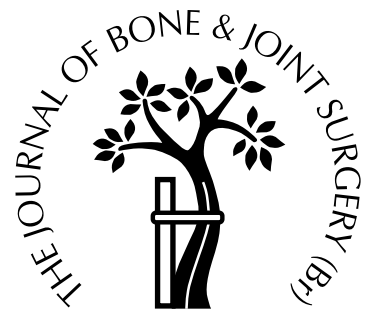

\title{
Editorial
}

\section{HIP REPLACEMENT AUDIT}

\author{
J. Nolan, H. Phillips
}

The outcome of most hip replacements performed in the UK remains unknown. While the results of certain prostheses are reported intermittently, usually by enthusiastic innovators working in specialist centres, it is rare that these outcomes are reviewed independently. It may be unreasonable to expect a busy orthopaedic surgeon in a District General Hospital to match such results. The paper by Fender, Harper and Gregg in this issue of the Journal (pp 577-81) describing the outcome at five years of the Charnley implant across a single region in the UK, suggests that this is indeed the case.

Recent reports of the premature failure of a total hip replacement (THR) ${ }^{1}$ have induced a state of anxiety among some patients, surgeons and the government. It is now clear, however, that 'clinical governance' will require precise surveillance of all THRs at Trust level.

There have been strong demands for a National Hip Register. The logistics of such an initiative have yet to be fully appraised. The organisation would require collection of data from all 40000 primary hip replacements annually which, even using electronic methods, would be costly. The value of reiterating many of the messages from the Scandinavian registers may be limited. An initial step, however, can now be taken. Orthopaedic surgeons should agree a national standard of data collection from all operations for primary

J. Nolan, FRCS Orth, Consultant Orthopaedic Surgeon

H. Phillips, FRCS, Consultant Orthopaedic Surgeon

Norfolk and Norwich Healthcare NHS Trust, Brunswick Road, Norwich NR1 3SR, UK.

(C)1999 British Editorial Society of Bone and Joint Surgery

0301-620X/99/410237\$2.00

J Bone Joint Surg [Br] 1999;81-B:565. hip replacement. NHS Trusts and private hospitals should ensure that the resources needed to record the basic information on the index procedure and all further operations on that joint are made available. Meaningful comparative audit will only be possible if data on casemix and co-morbidity are collected and this will require additional resources. Sampling information on a regional or national basis would, in time, enable standards to be set and would also identify poor performance of both implants and surgeons.

The present European directive does not offer sufficient protection to patients from the premature failure of hip implants since there is no legal obligation to perform longterm trials. We agree with Fender and Harper that, irrespective of this weak directive, all unproven hip implants, including 'look-alikes', should be subject to a more structured and prolonged period of surveillance. The directive provides no immunity against the 'creeping substitution' of incremental change experienced even by those prostheses for which long-term follow-up has been reported, and cannot influence the many other factors which affect the outcome of hip replacement, the most important of which, perhaps, is surgical technique.

Their study supports the view that all THRs should be subject to regular review in the long term. We owe it to our patients to be able to offer advice concerning the choice of a particular implant based upon relevant data, and to ourselves, as orthopaedic surgeons, to be able to maintain our own surgical performance.

\section{References}

1. Muirhead-Allwood SK. Editorial. Lessons of a hip failure: if we want improved prostheses we must regulate their use. BMJ 1998;316:644.

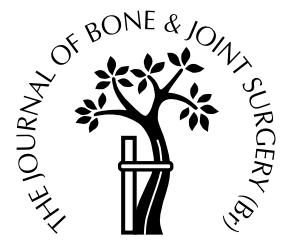

\section{Editorial}

\section{DOES THROMBOPHILIA CAUSE PERTHES' DISEASE IN CHILDREN?}

\author{
R. J. Liesner
}

During the last decade our understanding of the pathogenesis of venous and arterial thrombosis has been advanced significantly by the discovery of a number of highly prevalent genetic mutations which predispose to the development of thrombotic events in adults, often in combination with environmental factors such as the combined oral contraceptive pill and pregnancy. Our understanding, however, of the role of inherited thrombophilia in childhood disease is 
still relatively limited mainly because thromboses are rare in children and collaboration is necessary in order to advance knowledge in the diagnosis and management of these problems. Currently, there is considerable interest in the role of inherited and acquired prothrombotic disorders in the pathogenesis of a number of paediatric conditions such as childhood stroke, neonatal renal vein thrombosis, thrombosis related to central venous lines and in Perthes' disease. The last has been the subject of a number of recent studies, including two in this issue of the journal (pp 686-695).

The earliest comprehensive investigations on whether inherited thrombophilia may be related to Perthes' disease were published by Glueck et al. ${ }^{1,2}$ Their principal findings were that up to one-third of 64 children with this disorder had resistance to activated protein C (APC), currently the commonest cause of inherited thrombophilia. However, only a half of the children with APC resistance, 12 in all, had a confirmatory polymerase chain reaction (PCR) to show that resistance was due to the presence of the factor $\mathrm{V}$ Leiden (FVL) mutation. Eight had the mutation with one homozygote. In a control group the prevalence of this factor was only $1 \%$. In a later paper the same group ${ }^{3}$ showed that the 'standard' APC resistance assay used to screen for the FVL mutation was a poor predictor of the mutation. Ideally, a 'modified' assay should be used which adds factor-V-deficient plasma and therefore dilutes out other abnormalities which may affect the activated partial thromboplastin time. This means, however, that other possible abnormalities such as high levels of factor VIII which can cause 'acquired' APC resistance, will not be detected, but at present the role of this in thrombosis is unproven. An additional finding was an apparently 'low' protein-C antigen level in $28 \%$ of the 64 patients studied by Glueck et al, ${ }^{1,2}$ but the authors did not use age-adjusted normal ranges for protein $\mathrm{C}$. These take account of the normal physiological deficiency which is present until adulthood and their use would have diminished the number of patients with apparent low levels.

Subsequently, there have been a number of smaller studies which do not support the findings of Glueck et al. The articles in this issue of the journal (pp 686-695) produce no real evidence to show that thrombophilia plays a role in the development of Perthes' disease. The paper from Wales (p. 691) examines 64 children but since it is an observational study without controls it must be interpreted with caution. The authors have carefully adopted estab-

R. J. Liesner, MRCP, MRCPath, Lecturer in Paediatric Haematology Department of Haematology and Oncology, Great Ormond Street Hospital for Children, Great Ormond Street, London WC1N 5JH, UK.

(C)1999 British Editorial Society of Bone and Joint Surgery

0301-620X/99/410214 \$2.00

J Bone Joint Surg [Br] 1999;81-B:565-6. lished age-adjusted normal ranges for protein $\mathrm{C}$; none of their children showed a deficiency. One child, however, had protein-S deficiency, another was on the borderline and four had APC resistance using the modified assay. There were no confirmatory PCR results for the FVL mutation but it is highly likely that at least one of these children was homozygous for this mutation, which is present in $<0.1 \%$ of the population in the UK. The antithrombin levels were borderline in three children.

The other study (p. 686) had controls although they were not completely age-matched. Of 62 children with Perthes' disease one probably has inherited protein-S deficiency and both one patient and one control were protein-C-deficient. There were five children in the control group with the FVL mutation with two heterozygotes and one homozygote among the patients. There are two other prevalent mutations which are associated with an increased thrombophilic risk, namely the prothrombin gene polymorphism (PT20210) and the thermolabile variant of methylene tetrahydrofolate reductase (MTHFR-T) but these were found in few of the children. Similar observations have been made in a study of 61 Brazilian children.

These findings are contrary to those observed by Glueck et $\mathrm{al}^{1,2}$. We now need a controlled, perhaps multicentre, investigation with centralised or co-ordinated testing, in which orthopaedic surgeons liase with haematologists in order to give a proper answer. The balance of evidence to date shows that in most children thrombophilia plays no role in Perthes' disease. A few, however, do have significant inherited thrombophilia, including a small number with homozygosity for the FVL mutation, and it may be that this is one risk factor in a complex pathophysiological mechanism which requires the presence of other factors to result in the development of clinical disease. It is unlikely that inherited thrombophilia is the sole cause of Perthes' disease in most cases not least because these familial deficiencies and mutations have autosomal inheritance while Perthes' disease has a preponderance of 4/5:1 in boys, although the increase in incidence in families does suggest that there may be some inherited factors responsible. Reports of Perthes' disease in children with coexistent bleeding disorders, such as haemophilia and immune thrombocytopenia, again support the lack of an association.

\section{References}

1. Glueck CJ, Crawford A, Roy D, et al. Association of antithrombotic factor deficiencies and hypofibrinolysis with Legg-Perthes disease. $J$ Bone Joint Surg [Am] 1996;78-A:3-13.

2. Glueck CJ, Brandt G, Gruppo R, et al. Resistance to activated protein C and Legg-Perthes disease. Clin Orthop 1997;338:139-52.

3. Brandt G, Gruppo R, Glueck CJ, et al. Sensitivity, specificity and predictive value of modified assays for activated protein $\mathrm{C}$ resistance in children. Thromb Haemost 1998;78:567-70.

4. Arruda VR, Belangero WD, Ozelo MC, et al. Inherited risk factors for thrombophilia among children with Legg-Calvé-Perthes disease. Abstract 3204 ASH conference, 1997. 